\title{
Review
}

\section{Repairing the Brain: Cell Replacement Using Stem Cell-Based Technologies}

\author{
Claire Henchcliffe ${ }^{\mathrm{a}, *}$ and Malin Parmar ${ }^{\mathrm{b}, *}$ \\ ${ }^{a}$ Department of Neurology, Weill Cornell Medical College, and Department of Neurosurgery, \\ Memorial Sloan Kettering Cancer Center, New York NY, USA \\ ${ }^{\mathrm{b}}$ Wallenberg Neuroscience Center and Lund Stem Cell Center, Lund University, BMC, Lund, Sweden
}

Accepted 17 October 2018

\begin{abstract}
Current approaches to cell replacement therapy in Parkinson's disease are strongly focused on the dopamine system, with the view that restoring dopaminergic inputs in a localized and physiologic manner will provide superior benefits in terms of effect and longevity compared with oral medication. Experience using transplants of fetal tissue containing dopaminergic cell precursors has provided valuable proof that the approach is feasible, and that engrafted cells can survive and function over many years. However, multiple drawbacks and procedural complications are recognized in using fetal cells. Recent strides in stem cell technology now make it possible to overcome some of the barriers associated with fetal tissue. In particular the generation of high numbers of specific cell types, such as dopaminergic neurons, from stem cells means that quality, consistency, activity, and safety can be more thoroughly determined prior to transplantation, thus providing hope for more robust outcomes. These cells are also predicted to provide benefit without leading to the graft-induced dyskinesia that led to morbidity in a subset of individuals who underwent fetal mesencephalic cell and tissue grafting in the 1990s. In thinking about developing such novel therapeutics, the choice of starting material has also expanded, with the availability of multiple human embryonic stem cell lines, as well as the possibilities for producing induced pluripotent cells, or neuronal cells from a patient's own tissue. In this article, we speculate on how rapidly expanding knowledge and technical possibilities may impact on stem cell-based therapies for cell replacement in Parkinson's disease over the next two decades.
\end{abstract}

Keywords: Dopamine neurons, Parkinson's disease, stem cell therapy

\section{BACKGROUND}

Parkinson's disease (PD) is the second most common neurodegenerative disease worldwide, yet remains without a cure, and available treatments are widely agreed to have significant limitations in the long term. Despite its heterogeneity, the core

\footnotetext{
*Correspondence to: Claire Henchcliffe, Department of Neurology, Weill Cornell Medical College, 428 East 72nd Street, Suite 400, New York, NY 10021, USA. Tel.: +1 212746 2584; E-mail: clh2007@med.cornell.edu. and Malin Parmar, Wallenberg Neuroscience Center and Lund Stem Cell Center, Lund University, BMC A11, 22184 Lund, Sweden. Tel.: +46 46 2220620; E-mail: malin.parmar@med.lu.se.
}

pathology that is common to all patients is the loss of dopamine (DA) neurons in the midbrain. These midbrain DA neurons send their projections to the striatum where they release DA, which is needed to accurately modulate initiation and execution of movement. As the DA neurons degenerate, lower DA levels in the striatum cause the characteristic motor symptoms of the disease. The most common treatment provided today is based on enhancing the activity of the nigro-striatal pathway with DAmodulating therapies, thereby increasing the striatal DA levels, and thus improving the motor impairment associated with the disease. While these dopaminergic (DAergic) treatments are highly effective initially, 
they eventually lead to the development of a number of troublesome side effects such as on-off phenomena, and L-dopa induced dyskinesia (LID). Moreover, their administration may be limited by side effects that can include hallucinations and other psychiatric problems [1]. This is explained by temporally and spatially dysregulated DA delivery resulting from DAergic medication intake. A better way of treating the DA responsive aspects of PD would therefore be to target the DA replacement locally at the site of action (i.e., the striatum) and to regulate the release as closely as possible to physiological conditions.

Historically, and in the majority of current efforts underway or planned, cell replacement therapy for PD has been focused upon the characteristic striatal DAergic deficit, based on the idea that replacing the lost DA neurons with new healthy cells would result in DA release only where it is needed, and with a smooth temporal profile as close to physiologic delivery as possible. The approach was pioneered in Lund over 30 years ago, using fetal cells obtained from the midbrain of aborted embryos and, since then, a few hundred patients have received such transplants. Other donor cell sources tested include autologous adrenal medulla and carotid body tissue (dopamine-producing tissues requiring invasive procedures for harvest) that in clinical trials resulted in poor cell survival, and variable and modest benefit at best [2,3]. More recently, retinal pigment epithelial cells (RPE) delivered in a gelatin sphere (Spheramine $^{\circledR}$ ) provided no significant benefit compared with controls in a sham surgery controlled clinical trial [4], likely related to poor cell survival [5]. However, studies of fetal cell transplantation in PD have provided proof-of-principle that effective and long term repair can be achieved by cell transplantation [6], and in some cases, study participants were able to reduce or stop their anti-PD medications [7]. Unfortunately, despite some successes the overall outcomes have been highly variable. Although some patients have showed a restoration to "normality" of striatal DAergic innervation along with long term clinical benefit, others have had minor or no effect of their transplants, and some even experienced debilitating side effects, in particular graft induced dyskinesia (GID) [6]. Since at least some of the variability is likely from differences in the subjects transplanted, different surgical approaches, and different outcome measures, a new clinical trial called TRANSEURO using fetal cells is underway, with an optimized design that includes a study cohort based upon careful analysis of previous trials, standardized and reproducible surgical placement protocols, and with long term follow up using robust outcome measures ( http://www.transeuro.org.uk). This should address many of the problems noted above but, unfortunately, lack of uniformity in fetal tissue together with limited access means that it can never become a main line therapy.

In the future, use of cells derived from renewable and bankable sources that can meet the demand of large patient populations is needed. The most promising such cell source today is pluripotent stem cells, from which authentic and functional DA neurons now can be obtained under conditions compliant with use in patients [8]. Stem cell-based therapies for PD are now rapidly moving towards use in clinical trials and several academic as well as industry efforts are well on their way to initiate clinical trials [9].

In this review, we discuss potential advantages and limitations of cell-based therapies as they are being tested or are envisaged for PD today, and present speculations on how a number of shortcomings and limitations might be mediated by an increased understanding of the disease itself and new approaches in next-generation transplantation-based cell therapies (Table 1).

\section{TOWARDS A MORE ROBUST CLINICAL OUTCOME}

Data from published clinical trials performed to date using fetal cells is promising, but raises concern about heterogeneity of clinical outcomes reported. Much of this can be related to inconsistency in: i) cell preparation, cell number and cell composition; ii) patient selection; iii) method and duration of immunosuppression; iv) outcome measures and study duration; v) surgical delivery (critically reviewed by Barker and colleagues [6]). While optimized clinical trial characteristics are key to the ongoing TRANSEURO study as noted above, standardized and sufficiently quality controlled cell preparations simply cannot be achieved with fetal cells. The age of the embryos varies and tissue dissection, no matter how careful, may result in samples with variable content of not only DA neuron progenitors, but also precursor cells for serotonergic and other neurons, glial cells, and elements of vasculature. With stem cells however, it is now possible to make very large quantities of uniform transplantable cells that can be cryopreserved $[10,11]$. This means that rigorous quality control, as well as efficacy and safety testing, 
Table 1

Summary of the three types of cell sources discussed in this review. Advantages of stem cells versus fetal tissue as donor cell source

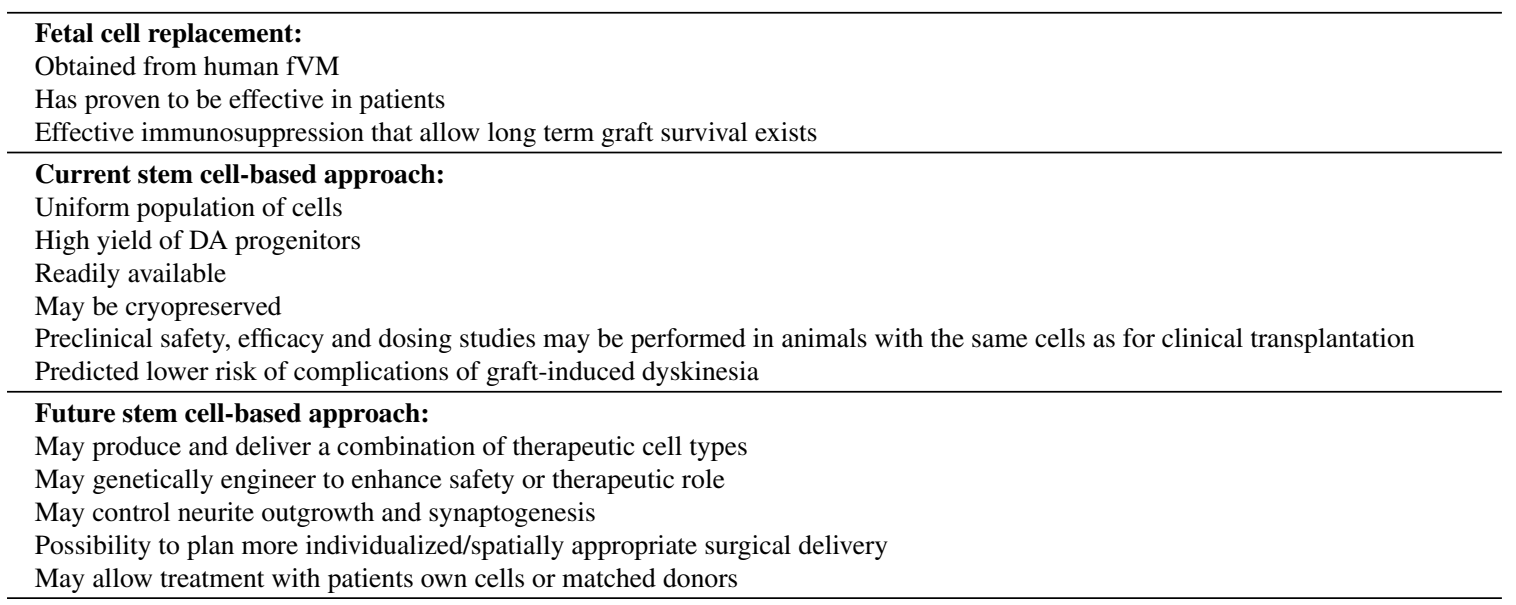

a)

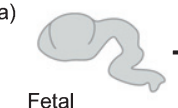

Fetal

mesencephalon

b)

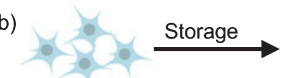

Stem cell-derived DA progenitors

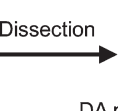

DA progenitors
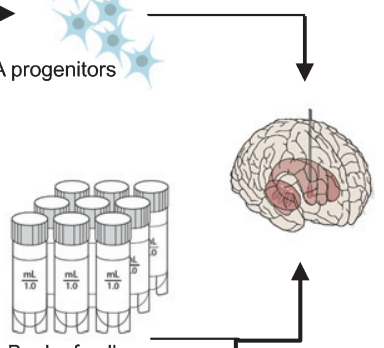

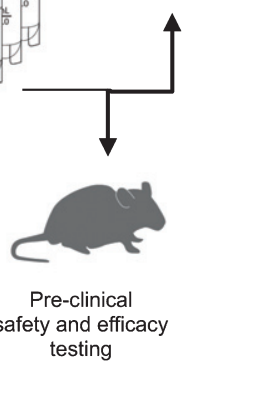

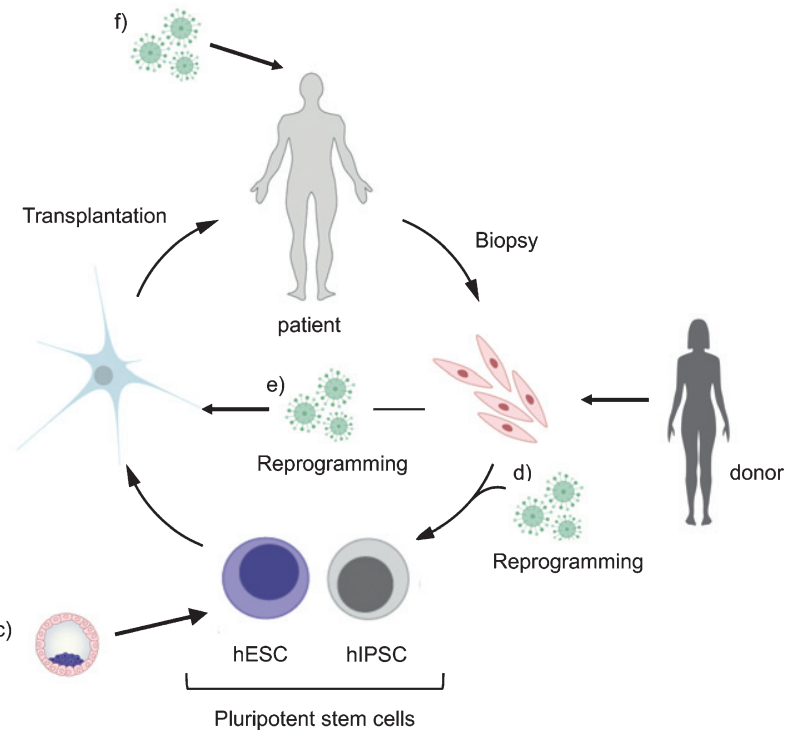

Fig. 1. Stem cells today and in the future. When using fetal cells for transplantation (a), tissue is collected and transplanted without the possibility for banking or quality assessment of the cells prior to transplantation. In contrast, DA progenitors derived from hESCs (b) can be banked and stored, allowing for extensive pre-clinical safety and efficacy testing of the cells prior to transplantation. Pluripotent stem cells can be obtained from pre-implantation blastocyst (c) or via reprogramming from fibroblasts (d) and differentiated into DA progenitors that mature into fully functional DA neurons after transplantation. In the case of iPSCs, they can be reprogrammed from matched donors or from the patients themselves. In the future, directly converted cells (e) or cells reprogrammed by viral injection into the brain (f) are attractive alternatives.

may be performed on the identical cell preparation that will subsequently be transplanted into patients (Fig. 1b). It also means that each patient in a trial will receive an identical cell preparation in a precisely specified amount, which is expected to reduce the variation in outcome significantly. Moreover, the availability of vials of cryopreserved cells that can be thawed at any time will greatly simplify surgical planning, and increase access to such therapies for study participants and eventually the PD community. Finally, although there remains much to learn, the existence of banks of cryopreserved cells not only opens the possibility for an "off the shelf" therapeutic that could be broadly available and distributed, but would also be the first step to a deeper understanding of therapeutic performance across varying patient 
types, that could result in being able to individualize dopamine neuron dose and cell delivery target in a heterogeneous patient population.

\section{AVOIDING GRAFT INDUCED DYSKINESIA}

Aside from variable clinical benefit for key features of $\mathrm{PD}$, there have also been concerns over variable tolerability, given that a subset of patients developed off-medication-state graft-induced dyskinesia (GID) after fetal cell transplantation $[12,13]$. The reasons behind emergence of GID are still debated but discussion has focused upon the presence of serotonergic (5HT) neurons in the graft, or "hot spots" of engrafted DA neurons resulting from uneven surgical delivery and/or growth.

5HT neurons have their embryological origin adjacent to the midbrain DA neurons and are co-mingled in the caudal region of the ventral midbrain. Thus it is not possible to completely remove them when dissecting and preparing fetal tissue for transplantation. These 5HT neurons in the graft might then result in dysregulated striatal DA contributing to dyskinesia. Moreover, not only is the presence of 5HT neurons in the graft a factor, but an elevated ratio of 5HT/DA neurons is also likely important as a cause of GID [14]. Therefore, removing donor 5HT neurons is expected to reduce the risk of GID significantly if not completely. From a stem cell source of neurons it is possible to more finely and precisely control cell differentiation and therefore to obtain cell preparations that are completely devoid of any 5HT neurons or precursors that might lead to GID. Moreover, with a large quantity of cells available, cell sorting strategies can be used to enrich for desired cells or remove unwanted contaminations.

GID may also arise from uneven spread of DA neurons after cell transplantation, resulting in DA "hot spots". In addition to surgical delivery considerations, donor tissue characteristics may also contribute to hot spots. It is well known that fetal cells of different stages generate a variable number of neurons with varying innervation capacity $[15,16]$, but it is not possible to predict DA yield or innervation capacity of such a tissue sample in the time frame necessary prior to grafting. Each patient undergoing fetal cell transplant receives a unique mix of cells from embryos at varying ages, and so DA hot spots cannot be securely eliminated. In contrast, when working with stem cell preparations, a major advantage is that aliquots of the same cells to be used in patients can be tested for phenotype, function, and outgrowth capacity in preclinical animal models (Fig. 1b), and this assessment can then be used to guide the number of cell deposits and tracts to be used for an optimal dispersal of cells to result in an even innervation of the putamen that is necessary for a good effect with minimal side effects. In the future, it may even be possible to introduce the cells with some type of matrix that would promote or guide outgrowth and innervation.

\section{ARE HUMAN EMBRYONIC STEM CELLS THE BEST OPTION?}

Human embryonic stem cells (hESCs) are actively being developed for clinical trials in PD by both academia and industry, and are expected to reach clinical trial later this year. The use of hESCs seems like a logical choice, given the richness of pre-clinical data supporting their use, and that a number of hESC lines meeting Good Manufacturing Practice (GMP) standards are already available.

However, there are other potential cell sources being actively explored as potential future treatments (Fig. 1c-e). The ability to reprogram cell fate using defined combinations of transcription factors [17] has transformed the field of regenerative medicine and opened up the possibility to obtain induced pluripotent stem cells (iPSCs) either from patients themselves or from immunologically matched donors $[18,19]$. This type of pluripotent stem cell responds to the same patterning cues as the hESCs and generates DA neurons of equal quality [20-23]. A recent study also showed that HLA matched grafting can be advantageous for cell survival and function [24]. However, the use of cells from immunologically matched donors further increases complexity and cost of stem cell based therapies. Nevertheless, iPSCs have already been used in clinical trials for macular degeneration [25] and are being actively pursued for PD [26].

In 2010, it was reported that skin cells could be directly reprogrammed into neurons without passing through a stem cell intermediate [27]. This type of direct conversion is generally considered as safer, since the pluripotent stage is completely avoided. Today, it is possible to generate DA neurons via direct conversion of human skin cells [28, 29], but they do not yet survive and function as well after transplantation as stem cell-derived DA neurons [30]. An interesting extension of direct cell fate conversion is 
to reprogram cells directly in the brain by injection of the conversion genes instead of cells. This has been achieved in rodent models and in transplanted human fibroblasts [31], but the precise dopamine identity of the in vivo reprogrammed neurons is still unclear [32-34]. Given time however, we predict that cellular conversion will become more and more refined [35], and it is not out of bounds to speculate that patients will be treated with healthy versions of their own cells in the future.

\section{PERSPECTIVE AND FUTURE GOALS}

Present efforts in cell replacement in PD are overwhelmingly focused on dopaminergic replacement and control of movement. The first generation of stem cell-derived DA neurons now in the pipeline is predicted to perform at least at an equivalent level to human fetal cells, but in a more robust and reproducible manner, providing a stable, expandable, and readily accessible cell source for transplantation. As such the therapy is expected to provide a better way of treating the DA responsive features of PD using a targeted, physiological delivery of DA to the striatum, but it is not a disease modifying treatment, nor a cure.

Many questions remain to be addressed.

- While immunosuppression is planned for transplantation of unmatched cells, the optimal approach remains unproven. Use of iPS-derived cells, that will provide wholly or partially matched donor cells for transplantation is already being addressed, but whether (and what) immunosuppression is truly required in the case of partially matched donors remains to be determined.

- PD pathology is not cell-autonomous, and the spread of pathology potentially affecting graft function is an oft-repeated although unsubstantiated objection to cell therapy. While current evidence supports absence of any major effect, it does raise the question of whether a combinatorial therapy comprising grafting and, for example, a biologic or small molecule to abrogate spread of alpha-synuclein pathology would be desirable.

- It is believed that obtaining even innervation from the graft would be advantageous, and so interventions that could promote neurite outgrowth and synaptogenesis need to be explored.
- A major area for research is whether and how genetic manipulation of cells for transplant could enhance therapeutic safety and impact, for example including a "suicide switch" in case of overgrowth, or incorporating a mechanism to deliver neuroprotective species, to combat further cell dysfunction in the host environment. Gene editing of the cells can also be done so that the graft function can be modulated using DREADDS (Designer Receptors Exclusively Activated by Designer Drugs) or optogenetics [36, 37].

- Despite the focus of this article on motor function, dopamine is known to impact upon various important non-motor aspects of PD, including learning, attention, reward, mood, and sleep. Is it possible that engrafting dopamine-producing donor cells could provide non-motor benefits? This idea has gained traction with recent findings that intrastriatal grafts of embryonic ventral mesencephalic tissue lead to improvements in behavioral testing in rats, including visuospatial performance and motivational processing [38].

- Moreover, in this article we have only discussed use of dopaminergic cells, whereas a stem cell source allows growth of any cell type. Other neural networks would be much more difficult to rebuild, but it is tempting to speculate that, for example, cholinergic cells could be helpful in addressing cognitive function, or balance.

There is a long road ahead in demonstrating how well stem cell-based reparative therapies will work, and much to understand about what, where, and how to deliver the cells, and to whom. But the massive strides in technology over recent years make it tempting to speculate that cell replacement may play an increasing role in alleviating at least the motor symptoms, if not others, in the decades to come

\section{ACKNOWLEDGMENTS}

We thank Ulrika Blank Savukinas for help with illustrations.

Dr. Parmar has received funding from the New York Stem Cell Foundation (MP), the European Research Council, the Swedish Research Council, the Swedish Parkinson Foundation (Parkinsonfonden), the Strategic Research Area at Lund University Multipark and Stem Therapy. Dr. Henchcliffe has received support from the National Institute of Neurological Disorders and Stroke, the National Center 
for Advancing Translational Science (NCATS), the Michael J. Fox Foundation, the C.V. Starr Foundation, New York State Department of Health /Empire State Stem Cell Board.

M.P. is a New York Stem Cell FoundationRobertson Investigator.

\section{CONFLICT OF INTEREST}

Dr. Parmar is the owner of Parmar Cells AB and co-inventor of the U.S. patent application 15/093,927 owned by Biolamina AB and EP17181588 owned by Miltenyi. Dr. Henchcliffe has received consultancies from US WorldMeds, Adamas Pharmaceuticals, and Prevail Therapeutics.

\section{REFERENCES}

[1] Connolly BS, Lang AE (2014) Pharmacological treatment of Parkinson disease: A review. JAMA 311, 1670-1683.

[2] Goetz CG, Stebbins GT, Klawans HL, Koller WC, Grossman RG, Bakay RA, Penn RD (1991) United Parkinson Foundation Neurotransplantation Registry on adrenal medullary transplants: Presurgical, and 1- and 2-year follow-up. Neurology 41, 1719-1722.

[3] Minguez-Castellanos A, Escamilla-Sevilla F, Hotton GR, Toledo-Aral JJ, Ortega-Moreno A, Mendez-Ferrer S, Martin-Linares JM, Katati MJ, Mir P, Villadiego J, Meersmans M, Perez-Garcia M, Brooks DJ, Arjona V, Lopez-Barneo J (2007) Carotid body autotransplantation in Parkinson disease: A clinical and positron emission tomography study. J Neurol Neurosurg Psychiatry 78, 825-831.

[4] Gross RE, Watts RL, Hauser RA, Bakay RA, Reichmann H, von Kummer R, Ondo WG, Reissig E, Eisner W, SteinerSchulze H, Siedentop H, Fichte K, Hong W, Cornfeldt M, Beebe K, Sandbrink R, Spheramine Investigational Group (2011) Intrastriatal transplantation of microcarrierbound human retinal pigment epithelial cells versus sham surgery in patients with advanced Parkinson's disease: A double-blind, randomised, controlled trial. Lancet Neurol 10, 509-519.

[5] Farag ES, Vinters HV, Bronstein J (2009) Pathologic findings in retinal pigment epithelial cell implantation for Parkinson disease. Neurology 73, 1095-1102.

[6] Barker RA, Drouin-Ouellet J, Parmar M (2015) Cell-based therapies for Parkinson disease-past insights and future potential. Nat Rev Neurol 11, 492-503.

[7] Kefalopoulou Z, Politis M, Piccini P, Mencacci N, Bhatia K, Jahanshani M, Widner H, Rehncrona S, Brundin P, Bjorklund A, Lindvall O, Limousin P, Quinn N, Foltynie T (2014) Long-term clinical outcome of fetal cell transplantation for Parkinson disease: Two case reports. JAMA Neurol 71, 83-87.

[8] Nolbrant S, Heuer A, Parmar M, Kirkeby A (2017) Generation of high-purity human ventral midbrain dopaminergic progenitors for in vitro maturation and intracerebral transplantation. Nat Protoc 12, 1962-1979.

[9] Barker RA, Parmar M, Studer L, Takahashi J (2017) Human trials of stem cell-derived dopamine neurons for Parkinson's disease: Dawn of a new era. Cell Stem Cell 21, 569-573.
[10] Kirkeby A, Parmar M, Barker RA (2017) Strategies for bringing stem cell-derived dopamine neurons to the clinic: A European approach (STEM-PD). Prog Brain Res 230, 165-190.

[11] Studer L (2017) Strategies for bringing stem cell-derived dopamine neurons to the clinic-The NYSTEM trial. Prog Brain Res 230, 191-212.

[12] Freed CR, Greene PE, Breeze RE, Tsai WY, DuMouchel W, Kao R, Dillon S, Winfield H, Culver S, Trojanowski JQ, Eidelberg D, Fahn S (2001) Transplantation of embryonic dopamine neurons for severe Parkinson's disease. $N$ Engl J Med 344, 710-719.

[13] Olanow CW, Goetz CG, Kordower JH, Stoessl AJ, Sossi V, Brin MF, Shannon KM, Nauert GM, Perl DP, Godbold J, Freeman TB (2003) A double-blind controlled trial of bilateral fetal nigral transplantation in Parkinson's disease. Ann Neurol 54, 403-414.

[14] Politis M, Oertel WH, Wu K, Quinn NP, Pogarell O, Brooks DJ, Bjorklund A, Lindvall O, Piccini P (2011) Graftinduced dyskinesias in Parkinson's disease: High striatal serotonin/dopamine transporter ratio. Mov Disord 26, 1997 2003.

[15] Annett LE, Torres EM, Clarke DJ, Ishida Y, Barker RA, Ridley RM, Baker HF, Dunnett SB (1997) Survival of nigral grafts within the striatum of marmosets with 6-OHDA lesions depends critically on donor embryo age. Cell Transplant 6, 557-569.

[16] Freeman TB, Sanberg PR, Nauert GM, Boss BD, Spector D, Olanow CW, Kordower JH (1995) The influence of donor age on the survival of solid and suspension intraparenchymal human embryonic nigral grafts. Cell Transplant 4, 141-154.

[17] Takahashi K, Yamanaka S (2006) Induction of pluripotent stem cells from mouse embryonic and adult fibroblast cultures by defined factors. Cell 126, 663-676.

[18] iPSCs: 10 years and counting. Cell 165, 1041-1042.

[19] Takahashi K, Yamanaka S (2016) A decade of transcription factor-mediated reprogramming to pluripotency. Nat Rev Mol Cell Biol 17, 183-193.

[20] Kriks S, Shim JW, Piao J, Ganat YM, Wakeman DR, Xie Z, Carrillo-Reid L, Auyeung G, Antonacci C, Buch A, Yang L, Beal MF, Surmeier DJ, Kordower JH, Tabar V, Studer L (2011) Dopamine neurons derived from human ES cells efficiently engraft in animal models of Parkinson's disease. Nature 480, 547-551.

[21] Doi D, Samata B, Katsukawa M, Kikuchi T, Morizane A, Ono Y, Sekiguchi K, Nakagawa M, Parmar M, Takahashi J (2014) Isolation of human induced pluripotent stem cell-derived dopaminergic progenitors by cell sorting for successful transplantation. Stem Cell Reports 2, 337-350.

[22] Lehnen D, Barral S, Cardoso T, Grealish S, Heuer A, Smiyakin A, Kirkeby A, Kollet J, Cremer H, Parmar M, Bosio A, Knobel S (2017) IAP-based cell sorting results in homogeneous transplantable dopaminergic precursor cells derived from human pluripotent stem cells. Stem Cell Reports 9, 1207-1220.

[23] Kikuchi T, Morizane A, Doi D, Magotani H, Onoe H, Hayashi T, Mizuma H, Takara S, Takahashi R, Inoue H, Morita S, Yamamoto M, Okita K, Nakagawa M, Parmar M, Takahashi J (2017) Human iPS cell-derived dopaminergic neurons function in a primate Parkinson's disease model. Nature 548, 592-596.

[24] Morizane A, Kikuchi T, Hayashi T, Mizuma H, Takara S, Doi H, Mawatari A, Glasser MF, Shiina T, Ishigaki H, Itoh 
Y, Okita K, Yamasaki E, Doi D, Onoe H, Ogasawar K, Yamanaka S, Takahashi J (2017) MHC matching improves engraftment of iPSC-derived neurons in non-human primates. Nat Commun 8, 385.

[25] Mandai M, Kurimoto Y, Takahashi M (2017) Autologous induced stem-cell-derived retinal cells for macular degeneration. $N$ Engl J Med 377, 792-793.

[26] Takahashi J (2017) Strategies for bringing stem cell-derived dopamine neurons to the clinic: The Kyoto trial. Prog Brain Res 230, 213-226.

[27] Vierbuchen T, Ostermeier A, Pang ZP, Kokubu Y, Sudhof TC, Wernig M (2010) Direct conversion of fibroblasts to functional neurons by defined factors. Nature 463, 10351041.

[28] Pfisterer U, Kirkeby A, Torper O, Wood J, Nelander J, Dufour A, Bjorklund A, Lindvall O, Jakobsson J, Parmar M (2011) Direct conversion of human fibroblasts to dopaminergic neurons. Proc Natl Acad Sci U S A 108, 10343-10348.

[29] Caiazzo M, Dell'Anno MT, Dvoretskova E, Lazarevic D, Taverna S, Leo D, Sotnikova TD, Menegon A, Roncaglia P, Colciago G, Russo G, Carninci P, Pezzoli G, Gainetdinov RR, Gustincich S, Dityatev A, Broccoli V (2011) Direct generation of functional dopaminergic neurons from mouse and human fibroblasts. Nature 476, 224-227.

[30] Pereira M, Pfisterer U, Rylander D, Torper O, Lau S, Lundblad M, Grealish S, Parmar M (2014) Highly efficient generation of induced neurons from human fibroblasts that survive transplantation into the adult rat brain. Sci Rep $\mathbf{4}$, 6330.

[31] Torper O, Pfisterer U, Wolf DA, Pereira M, Lau S, Jakobsson J, Bkorklund A, Grealish S, Parmar M (2013) Generation of induced neurons via direct conversion in vivo. Proc Natl Acad Sci U S A 110, 7038-7043.
[32] Torper O, Ottosson DR, Pereira M, Lau S, Cardoso T, Grealish S, Parmar M (2015) In vivo reprogramming of striatal NG2 glia into functional neurons that integrate into local host circuitry. Cell Rep 12, 474-481.

[33] Pereira M, Birtele M, Shrigley S, Benitez JA, Hedlund E, Parmar M, Ottosson DR (2017) Direct reprogramming of resident NG2 glia into neurons with properties of fastspiking parvalbumin-containing interneurons. Stem Cell Reports 9, 742-751.

[34] Rivetti di Val Cervo P, Romanov RA, Spigolon G, Masini D, Martin-Montanez E, Toledo EM, La Manno G, Feyder M, Pifl C, Ng YH, Sanchez SP, Linnarsson S, Wernig M, Harkany T, Fisone G, Arenas E (2017) Induction of functional dopamine neurons from human astrocytes in vitro and mouse astrocytes in a Parkinson's disease model. Nat Biotechnol 35, 444-452.

[35] Barker RA, Gotz M, Parmar M (2018) New approaches for brain repair-from rescue to reprogramming. Nature 557, 329-334.

[36] Aldrin-Kirk P, Heuer A, Wang G, Mattsson B, Lundblad M, Parmar M. Bjorklund T (2016) DREADD modulation of transplanted DA neurons reveals a novel parkinsonian dyskinesia mechanism mediated by the serotonin 5-HT6 receptor. Neuron 90, 955-68.

[37] Steinbeck JA, Choi SJ, Mrejeru A, Ganat Y, Deisseroth K, Sulzer D, Mosharov EV, Studer L (2015) Optogenetics enables functional analysis of human embryonic stem cell-derived grafts in a Parkinson's disease model. Nat Biotechnol 33, 204-209.

[38] Lelos MJ, Morgan RJ, Kelly CM, Torres EM, Rosser AE, Dunnett SB (2016) Amelioration of non-motor dysfunctions after transplantation of human dopamine neurons in a model of Parkinson's disease. Exp Neurol 278, 54-61. 